\title{
COMPENSACIÓN ECONÓMICA Y LIMITES A LA AUTONOMÍA DE LA VOLUNTAD: CADUCIDAD, INMUTABILIDAD Y RENUNCIA ANTICIPADA*
}

\author{
ECONOMIC COMPENSATION AND LIMITS TO THE AUTONOMY OF THE \\ WILL: EXPIRY, IMMUTABILITY AND EARLY DISCLAIMER
}

\author{
NATALIA DE LA TORRE*
}

\begin{abstract}
Resumen: El Código Civil y Comercial argentino ha incorporado la posibilidad de peticionar o acordar una compensación económica post divorcio o cese de la unión convivencial. En torno a esta figura han surgido diversos debates que transitan sobre un tópico común: los límites justificados a la autonomía de la voluntad. Entre ellos se destacan las discusiones sobre: a) la posibilidad de modificar una compensación económica acordada o fijada judicialmente, b) el modo de contabilizar el plazo de caducidad y la validez de la declaración de caducidad de oficio y c) la posibilidad de renunciar anticipadamente a la compensación económica mediante un pacto de convivencia. Concluyendo que, al ser la compensación económica una herramienta que permite acceder a recursos económicos que permitan la autonomía futura, los límites planteados por el legislador al regular este instituto, así como las interpretaciones de la judicatura y/o doctrina que aseguran el acceso a esta herramienta, están plenamente justificados.
\end{abstract}

Palabras clave: compensación económica, límites a la autonomía de la voluntad, normativa argentina, divorcio, unión convivencial.

Abstract: The Argentine Civil and Commercial Code, has incorporated the possibility of requesting or agreeing to financial compensation post-divorce or cohabitation ceases. Around this figure have arisen diverse debates that go on a common topic: the justified limits to the autonomy of the will. Among them, the following stand out: a) the possibility of modifying an agreed or judicially fixed financial compensation, b) the way of counting the expiration period and the validity of the ex officio expiration declaration and c) the possibility of waiving in advance to financial compensation through a pact of coexistence. Concluding that, as economic compensation is a tool that allows access to economic resources that allow future autonomy, the limits set by the legislator in regulating this institute, as well as interpretations of the judiciary and / or doctrine that ensure access to this tool, they are fully justified.

Keywords: economic compensation, limits to the autonomy of the will, Argentine regulations, divorce, cohabitation.

* http://doi.org/10.15366/rjuam2018.38.003

Fecha de recepción: 8 de noviembre de 2018.

Fecha de aceptación: 19 de diciembre de 2018.

** Abogada (UBA), Profesora de Filosofía (UBA). Jefa de Trabajos Prácticos Derecho de Familia y Sucesiones, Facultad de Derecho, UBA. Profesora Adjunta de Derecho de Familia y Sucesiones, Universidad Nacional de Avellaneda. Correo electrónico: delatorre.natalia@gmail.com. 
SUMARIO: I. PALABRAS INTRODUCTORIAS. II. COMPENSACIÓN ECONÓMICA Y DIVORCIO; 1. Convenciones prematrimoniales y matrimoniales; 2. Convenio Regulador y Compensación Económica; 3. Modificación de la Compensación Económica acordada o fijada judicialmente; 4. Caducidad y Compensación Económica. III. COMPENSACIÓN ECONÓMICA Y CESE DE LA UNIÓN CONVIVENCIAL; 1. Consideraciones previas; 2. Dos pronunciamientos jurisprudenciales de interés; 3. Debate: ¿se puede renunciar anticipadamente a la compensación económica? IV. BREVES PALABRAS DE CIERRE. V. BIBLIOGRAFÍA.

\section{PALABRAS INTRODUCTORIAS}

La presente colaboración, inserta en un número dedicado a analizar el cruce entre autonomía de la voluntad o principio de libertad y orden público en las relaciones de familia como desafío del siglo XXI en España y América Latina, tiene por objeto abordar una arista particular relacionada con los efectos patrimoniales post ruptura de las relaciones de pareja, sean estas de origen matrimonial o convivencial. Me refiero al novel instituto de la compensación económica introducido en el ordenamiento jurídico argentino en el Código Civil y Comercial (en adelante, CCyC) sancionado en octubre de 2014 y en vigencia desde el primero de agosto del año 2015.

Ahora bien, antes de adentrarnos en el análisis particular de la regulación de esta figura es preciso caracterizar, de manera harto sintética, el cambio de paradigma operado en el derecho argentino respecto al modo de entender a las familias denominado como la constitucionalización y convencionalización del Derecho privado ${ }^{1}$. Esto nos permitirá comprender o incluso cuestionar los alcances de la normativa prevista para la compensación económica como efecto derivado del divorcio o cese de la unión convivencial.

Este paradigma se construye en Argentina a partir de la reforma constitucional del año 1994 que incorpora con jerarquía constitucional distintos tratados de derechos humanos que conforman lo que se conoce como bloque constitucional federal (art. 75, inc. 22, CN).

A diferencia de lo que ocurre en otros países, Argentina cuenta desde el texto normativo supremo con un concepto abierto, poroso y amplio de familia. El artículo 14 bis de nuestra carta magna, en lo que aquí interesa, reza:

«El Estado otorgará los beneficios de la seguridad social, que tendrá carácter de integral e irrenunciable. En especial, la ley establecerá: el seguro social obligatorio, que estará a cargo de entidades nacionales o provinciales con autonomía financiera y económica, administradas por los interesados con participación del Estado, sin

\footnotetext{
1 Para profundizar sobre el concepto de constitucionalización del derecho de familia se recomienda compulsar, entre otros tantos: GIL DOMÍNGUEZ, A., FAMÁ, M. V. y HERRERA, M., Derecho Constitucional de Familia, Buenos Aires (Ediar), 2006; y LLOVERAS, N. y SALOMÓN, M., El derecho de familia desde la Constitución Nacional, Buenos Aires (Editorial Universidad), 2009.
} 
que pueda existir superposición de aportes; jubilaciones y pensiones móviles; la protección integral de la familia; la defensa del bien de familia; la compensación económica familiar y el acceso a una vivienda digna».

Por otra parte, en nuestro sistema constitucional de derecho, los únicos límites legítimos y no arbitrarios de interferencia al principio de reserva o autonomía personal son: el daño a un tercero (neminem laedere), la protección de la propia autonomía y el interés general de una sociedad democrática ${ }^{2}$.

Asimismo, el interés general se interpreta dentro del respeto a las diversas identidades, creencias y tradiciones, sean culturales, religiosas, artísticas, literarias, sociales, políticas o étnicas que no vulneren los valores constitucionales (art. $168 \mathrm{CCyC}$ ).

Estas razones, en apretada síntesis, han obligado a repensar el orden público en consonancia con la doctrina de los derechos humanos. Esta será la hermenéutica adecuada para determinar cuánto de autonomía de la voluntad y cuánto de orden público debe contener el derecho de las familias, más particularmente, las relaciones de pareja post quiebre del matrimonio o cese de la unión convivencial.

En este sentido, en los Fundamentos del entonces Anteproyecto de Reforma y Unificación del Código Civil y Comercial, antecedente directo del código actual, se señala:

«La mirada rígida sobre las relaciones humanas familiares, bajo la excusa de considerar todo de orden público, contraría la noción de pluralismo que pregona la doctrina internacional de los Derechos Humanos. En efecto, existe un derecho a la vida familiar y, consecuentemente, la injerencia estatal tiene límites. Por eso, se introducen modificaciones de diversa índole a fines de lograr un mejor y mayor equilibrio en la clásica tensión entre autonomía de la voluntad y orden público».

En palabras de Borrillo:

«Ante la complejidad de las formas familiares a las que se encuentra confrontado el orden jurídico, es pertinente preguntarse si las reglas clásicas del derecho de familia basado en gran parte en el orden público pueden continuar gobernando de manera eficaz las relaciones familiares o si, por el contrario, se hace necesario pergeñar mecanismos nuevos que permitan regular de una manera flexible los diferentes modos de organización familiar» ${ }^{3}$.

2 Para profundizar sobre este tópico ver, GARGARELLA, R., «Constitucionalismo y privacidad», en GARGARELlA, R. (coord.) Teoría y Crítica del Derecho Constitucional, Buenos Aires (Abeledo Perrot), 2010, Tomo II, pp. 779-796.

3 BORILLO, D., «La contractualización de los vínculos de familia», Derecho de Familia. Revista Interdisciplinaria de Doctrina y Jurisprudencia, núm. 79, 2017. Disponible en $<\mathrm{https} / /$ hal.archives-ouvertes. fr/hal-01528614/document>. [Consultado el 7/11/2018]. 
El código, haciéndose eco de este interrogante, replantea la relación entre autonomía y orden público en términos de libertad con responsabilidad o solidaridad familiar. Reemplazando un derecho de familia unívoco, jerárquico y verticalista, sentado en el valor de la familia como «institución», por un derecho de las personas a vivir en familia.

Ahora bien, como adelantáramos, la finalidad de estas líneas no es estudiar el alcance del principio de autonomía y sus límites en todo el basto campo de las relaciones familiares en el derecho argentino, sino más bien circunscribir esta matriz de análisis a la figura de la compensación económica en tanto efecto previsto para el divorcio y para el cese de la unión convivencial.

La legislación civil y comercial con fundamento en el principio de solidaridad familiar y en que el matrimonio y la unión convivencial no sean causa de enriquecimiento o empobrecimiento económico de un cónyuge o conviviente a costa del otro, prevé la posibilidad de que en ambos tipos de organización familiar -aunque con diferencias en cuanto a regulación- sus integrantes puedan reclamar judicialmente o acordar compensaciones económicas entre sí.

En palabras de los Fundamentos que acompañaron al Anteproyecto, antecedente directo del Código Civil y Comercial:

«Al tratarse de una herramienta destinada a lograr un equilibrio patrimonial, es necesario realizar un análisis comparativo de la situación patrimonial de cada uno de los cónyuges al inicio del matrimonio y al momento de producirse el divorcio, esto es, obtener una "fotografía" del estado patrimonial de cada uno de ellos, y ante un eventual desequilibrio, proceder a su recomposición».

Los contornos de esta figura son definidos por el legislador en los artículos 441 -divorcio- y 524 -cese de la unión convivencial- del CCyC, estableciendo que el cónyuge o conviviente a quien el divorcio o cese de la unión convivencial le produce un desequilibrio manifiesto que signifique un empeoramiento de su situación, que tenga por causa adecuada el vínculo matrimonial o la unión convivencial y su ruptura, tiene derecho a una compensación.

En el caso del divorcio, esta compensación puede consistir en una prestación única, en una renta por tiempo determinado o, excepcionalmente, por plazo indeterminado. En cambio, ante el cese de la unión convivencial, solo puede consistir en una prestación única o una prestación por tiempo determinado que no puede ser mayor al tiempo de duración de la unión convivencial, eliminando la posibilidad -legal, no así por vía convencional- de que se establezca una renta por plazo indeterminado. 
Por su parte, los criterios de fijación judicial establecidos en los artículos $442^{4}$ y $525^{5}$ del CCyC evidencian que la compensación no tendrá en cuenta únicamente los bienes materiales - la faz cuantitativa de la capacidad económica de cada uno- sino, también, la faz cualitativa, es decir, el desarrollo profesional y educacional alcanzado en tanto herramienta proclive a obtener mejores condiciones económicas futuras.

Establecidos los lineamientos generales de la figura de la compensación económica como efecto del divorcio o cese de la unión, a continuación, desarrollaremos el estudio de algunas de las artistas de este instituto en dos apartados, uno destinado a la compensación económica en el divorcio y otro a la compensación económica ante el cese de una unión convivencial.

En el primer escenario -divorcio-, interesa traer a colación dos tópicos debatidos en el derecho argentino: a) la inmutabilidad o mutabilidad de las compensaciones económicas acordadas y homologadas por el juez o las fijadas judicialmente y b) la caducidad de la compensación económica en dos de sus extremos, desde cuándo comienza a correr el plazo de caducidad previsto por la norma y si es posible o no la declaración de oficio de la caducidad. Con este objetivo, como antesala, será preciso conocer los alcances de las convenciones prematrimoniales y matrimoniales, es decir, los límites a la autonomía de la voluntad impuestos por el ordenamiento jurídico, así como las notas típicas de lo que el código denomina «convenio regulador».

En el caso de las uniones convivenciales, en cambio, analizaremos la regulación en torno a los pactos de convivencias y los límites impuestos a la facultad pactar (arts. 513 y 515 del (CyC), sin dejar de lado las notas o elementos que definen la existencia de una unión convivencial y con ella sus efectos, para luego concentrarnos en la discusión doctri-

4 Artículo 442. Fijación judicial de la compensación económica. Caducidad. A falta de acuerdo de los cónyuges en el convenio regulador, el juez debe determinar la procedencia y el monto de la compensación económica sobre la base de diversas circunstancias, entre otras: a) el estado patrimonial de cada uno de los cónyuges al inicio y a la finalización de la vida matrimonial; b) la dedicación que cada cónyuge brindó a la familia y a la crianza y educación de los hijos durante la convivencia y la que debe prestar con posterioridad al divorcio; c) la edad y el estado de salud de los cónyuges y de los hijos; d) la capacitación laboral y la posibilidad de acceder a un empleo del cónyuge que solicita la compensación económica; e) la colaboración prestada a las actividades mercantiles, industriales o profesionales del otro cónyuge; f) la atribución de la vivienda familiar, y si recae sobre un bien ganancial, un bien propio, o un inmueble arrendado. En este último caso, quién abona el canon locativo. La acción para reclamar la compensación económica caduca a los seis meses de haberse dictado la sentencia de divorcio.

5 Artículo 525. Fijación judicial de la compensación económica. Caducidad. El juez determina la procedencia y el monto de la compensación económica sobre la base de diversas circunstancias, entre otras: a) el estado patrimonial de cada uno de los convivientes al inicio y a la finalización de la unión; b) la dedicación que cada conviviente brindó a la familia y a la crianza y educación de los hijos y la que debe prestar con posterioridad al cese; c) la edad y el estado de salud de los convivientes y de los hijos; d) la capacitación laboral y la posibilidad de acceder a un empleo del conviviente que solicita la compensación económica; e) la colaboración prestada a las actividades mercantiles, industriales o profesionales del otro conviviente; f) la atribución de la vivienda familiar. La acción para reclamar la compensación económica caduca a los seis meses de haberse producido cualquiera de las causas de finalización de la convivencia enumeradas en el artículo 523. 
naria sobre la posibilidad de renunciar anticipadamente a la compensación económica en este tipo de organización familiar.

En síntesis, dos son los interrogantes que acompañan estas líneas, uno genérico y otro más específico. ¿Los límites a la autonomía de la voluntad impuestos por el legislador y/o por la judicatura a la hora de implementar la figura de la compensación económica se encuentran justificados o resultan arbitrarios? En relación con los debates habidos en doctrina -inmutabilidad/mutabilidad, caducidad y renuncia anticipada a la compensación económica- la pregunta que nos servirá de guía para preferir una interpretación doctrinaria por sobre otra/s es la siguiente: ¿qué posicionamiento favorece mayormente la autonomía de los integrantes de un matrimonio o unión convivencial una vez producido el quiebre de la relación? Veamos.

\section{COPENSACIÓN ECONÓMICA Y DIVORCIO}

\section{Convenciones prematrimoniales y matrimoniales}

Un ejemplo claro de la democratización y revalorización del ejercicio de la autonomía que propugna el código argentino lo encontramos en la regulación de los efectos personales y patrimoniales del matrimonio.

En relación con los efectos personales, la legislación civil y comercial recepta un ejercicio pleno de autonomía estableciendo que los cónyuges se comprometen a desarrollar un proyecto de vida en común basado en la cooperación y el deber moral de fidelidad, debiéndose prestar asistencia recíproca (art. 431 del CCyC).

De este modo, la fidelidad y la cohabitación dejan de adjetivarse como derechosdeberes jurídicos derivados del matrimonio, consecuencia lógica de un sistema que ha derogado la figura del divorcio-sanción y ha adoptado un divorcio sin expresión de causa.

Por otra parte, la desaparición de las causales subjetivas, como razón sistémicapráctica de la supresión de estos deberes jurídicos, es acompañada con otra razón de índole sistémico-teórica; la fidelidad y la cohabitación son elementos que hacen al ámbito de reserva y libertad de las personas.

En la misma línea, la legislación civil y comercial, en resguardo a la autonomía futura de los integrantes del matrimonio, establece que es de ningún valor-nulidad-la renuncia a la facultad de peticionar el divorcio de cualquiera de los cónyuges (art. 436 del CCyC).

Ahora bien, como dijimos, el principio de autonomía no solo cobra fuerza en las relaciones personales de los cónyuges, también se ha incorporado en la regulación de la esfera patrimonial. ¿Cómo? Introduciendo la posibilidad de que los cónyuges puedan optar entre dos regímenes patrimoniales del matrimonio: el de comunidad o el de separación de 
bienes. ¿Qué sucede si no ejercen el derecho a opción? Aplicación supletoria del régimen de comunidad. ¿Cuándo pueden ejercer la opción? Antes de la celebración del matrimonio como convención matrimonial -art. 446, inc. d) del CCyC-y durante la vigencia del matrimonio por convención de los cónyuges en la que acuerden modificar el régimen, siempre que hayan cumplido un año de permanencia en el régimen anterior -art. 449 del CCyC-.

En síntesis, antes de celebrar el matrimonio, las convenciones (pre)matrimoniales solo pueden tener por objeto: a) la designación y avalúo de los bienes que cada uno lleva al matrimonio, b) la enunciación de las deudas, c) las donaciones que se hagan entre ellos y d) la opción que hagan por alguno de los regímenes patrimoniales previstos en este Código. La norma, además, establece la nulidad de cualquier otro tipo de acuerdo. «Toda convención entre los futuros cónyuges sobre cualquier otro objeto relativo a su patrimonio es de ningún valor» (art. 447 del CCyC).

En cambio, una vez celebrado el matrimonio, los cónyuges solo podrán convenir -por escritura pública- el cambio de régimen patrimonial (art. 449 del CCyC) y, para que dicho cambio produzca efectos respecto de terceros debe anotarse marginalmente en el acta de matrimonio.

De esta forma, el sistema veda la posibilidad de renuncia anticipada a la compensación económica en el marco de la vida matrimonial, en tanto como efecto del divorcio, solo será válida la renuncia expresa mediante inclusión de una cláusula en el convenio regulador o la renuncia tácita ante la falta de reclamo judicial posterior al divorcio -incluido el reclamo iniciado cumplido el plazo de caducidad de seis meses-.

No obstante, cabe destacar que, en el marco del Congreso Internacional de Derecho de las Familias, Niñez y Adolescencia realizado en Mendoza, Argentina en agosto de 2018, en la Comisión destinada a profundizar sobre la «Contractualización de las relaciones familiares patrimoniales. Empresa familiar, pactos convivenciales y convenio regulador», con criterio que compartimos, de lege data se concluyó:

«Los cónyuges casados bajo régimen de separación de bienes pueden realizar pactos de previsión de los efectos de la ruptura matrimonial, pues tienen plena libertad contractual ${ }^{6}$. Estos acuerdos pueden contener estipulaciones relativas a la compensación económica para el caso de divorcio. Su validez debe ser

\footnotetext{
6 Artículo 1002 del CCyC. Inhabilidades especiales. No pueden contratar en interés propio: a) los funcionarios públicos, respecto de bienes de cuya administración o enajenación están o han estado encargados; b) los jueces, funcionarios y auxiliares de la justicia, los árbitros y mediadores, y sus auxiliares, respecto de bienes relacionados con procesos en los que intervienen o han intervenido; c) los abogados y procuradores, respecto de bienes litigiosos en procesos en los que intervienen o han intervenido; d) los cónyuges, bajo el régimen de comunidad, entre sí.
} 
examinada en el caso concreto, sin que pueda sostenerse a priori que estos pactos son contrarios al orden público argentino» ${ }^{7}$.

\section{Convenio Regulador y Compensación Económica}

En el marco de la nueva legislación civil argentina el divorcio se decreta judicialmente a petición de uno o ambos cónyuges, sin tiempos de espera y sin alegación de causa. El único requisito procedimental que se exige para que la petición prospere es que sea acompañada por una propuesta que regule los efectos posteriores al dictado de la sentencia de divorcio, incluido el reclamo de una compensación económica ${ }^{8}$.

En caso de existir acuerdo entre los cónyuges respecto de los efectos posteriores al divorcio - este acuerdo puede ser parcial o total-se presentará un convenio regulador ${ }^{9}$ que puede -no debe- contener, entre otras, las cuestiones relativas a la atribución de la vivienda, la distribución de los bienes, las eventuales compensaciones económicas entre los cónyuges, el ejercicio de la responsabilidad parental y la prestación alimentaria (art. 439 del CCyC).

La doctrina ha destacado el lugar preponderante de la autonomía de la voluntad al momento de regular los efectos post divorcio: «La circunstancia de dar la posibilidad a las partes de incorporar al convenio los temas que en total libertad cada uno de los matrimonios considere importantes consagra el respeto por la autonomía de la voluntad de los cónyuges» ${ }^{10}$.

De conformidad con lo establecido en el artículo 440 del CCyC el convenio regulador homologado o la decisión judicial pueden ser revisados si la situación se ha modificado sustancialmente.

7 Disponible en: <http://congresoderechofamiliasmendoza.com/wp-content/uploads/2018/08/ CONCLUSIONES-COMISION-3.pdf $>$. [Consultado el 7/11/2018].

8 Artículo 438. Requisitos y procedimiento del divorcio. Toda petición de divorcio debe ser acompañada de una propuesta que regule los efectos derivados de este; la omisión de la propuesta impide dar trámite a la petición. Si el divorcio es peticionado por uno solo de los cónyuges, el otro puede ofrecer una propuesta reguladora distinta. Al momento de formular las propuestas, las partes deben acompañar los elementos en que se fundan; el juez puede ordenar, de oficio o a petición de las partes, que se incorporen otros que se estiman pertinentes. Las propuestas deben ser evaluadas por el juez, debiendo convocar a los cónyuges a una audiencia. En ningún caso el desacuerdo en el convenio suspende el dictado de la sentencia de divorcio. Si existe desacuerdo sobre los efectos del divorcio, o si el convenio regulador perjudica de modo manifiesto los intereses de los integrantes del grupo familiar, las cuestiones pendientes deben ser resueltas por el juez de conformidad con el procedimiento previsto en la ley local.

9 El convenio regulador puede presentarse al inicio del proceso de divorcio - petición bilateral-o puede acordarse durante el trámite de divorcio - petición unilateral o bilateral-. Para profundizar, compulsar, KEMELMAJER DE CARLUCCI, A. y HERRERA, M., «Convenio regulador en el divorcio. Respuestas a preguntas equivocadas», La Ley, 17/03/2015, 1, p. 1134.

10 DURAT, C., «Comentario al artículo 439», en KEMELMAJER DE CARLUCCI, A.; HERRERA, M. y LloverAS, N. (dirs.), Tratado de Derecho de Familia. Según el Código Civil y Comercial de 2014, Tomo I, Santa Fe (Rubinzal Culzoni), 2014, p. 403. 


\section{Modificación de la compensación económica acordada o fijada judicialmente}

En el marco sucintamente descripto, la compensación económica puede configurarse en dos escenarios que es preciso diferenciar: a) su inclusión por acuerdo de partes en el convenio regulador homologado por el juez y b) su fijación judicial ante petición de parte.

A diferencia de lo que ocurre en otros ordenamientos, por ejemplo, el caso de España ${ }^{11}$, la legislación argentina no prevé causales de extinción o modificación de compensaciones económicas acordadas y homologadas o fijadas judicialmente.

En ausencia de causales de modificación o extinción de la compensación económica, el debate doctrinario se ha concentrado en la interpretación del artículo 440 del Código Civil y Comercial. ¿Se puede modificar la compensación económica fijada judicialmente o acordada y homologada? ¿La posibilidad de revisar el convenio regulador o la decisión judicial si la situación se ha modificado sustancialmente, comprende también la revisión de la compensación económica?

En este contexto, y siempre dejando a un lado aquellos supuestos de convenios reguladores homologados que hayan previsto expresamente una condición resolutoria o una cláusula de revisión de la cuantía o la forma de pago, así como los convenios posteriores que contengan una cláusula de extinción o revisión de la compensación fijada o acordado con anterioridad ${ }^{12}$, se han presentado en doctrina dos posturas antagónicas y algunos matices. Veamos.

Por un lado, aquellos que sostienen la inmutabilidad de la compensación económica fijada o acordada fundan este carácter en los elementos o requisitos de procedencia de la figura, señalando que:

«Producido el desequilibrio luego del divorcio, el mismo será evaluado conforme las circunstancias que han ocurrido en esa familia, y en base a ello, se fijará el monto y la forma de pago; estas circunstancias no pueden ser modificadas una vez evaluadas, ya que se refieren a hechos anteriores a la separación y a circunstancias concretas que el divorcio ha producido en el aspecto económico» ${ }^{13}$.

\footnotetext{
11 Artículo 101 del CE.

12 Como se ha señalado: «[e]stos acuerdos son válidos y eficaces sino transgreden los límites del orden público. Por eso no pueden incluir una condición prohibida (art. 344, CCyC), como sucedería si se sujeta el pago a que el acreedor no mude su domicilio, no profese determinada religión o no vuelva a contraer matrimonio, pues ellas contrarían el principio de libertad». GRONDONA P., «Convenio regulador: cláusulas permitidas y prohibidas», Revista de Derecho Privado y Comunitario, núm. 2, 2016, p. 282, citado por MOLINA DE JUAN, M., Compensación Económica, Santa Fe (Rubinzal Culzoni), 2018, p. 292.

13 DUPRAT, C., «Comentario al artículo 440», en KEMELMAJER DE CARLUCCI, A.; HERRERA, M. y LLOVERAS, N. (dirs.), Tratado de Derecho de Familia. Según el Código Civil y Comercial de 2014, Tomo I, Santa Fe (Rubinzal Culzoni), 2014, p. 410.
} 
Por otro, aquellos que defienden la mutabilidad de la compensación económica concentran sus argumentos en torno a la redacción del artículo 440 del CCyC:

«Lo cierto es que, de ocurrir un cambio sustancial en las circunstancias que sirvieron de base para la determinación de la compensación y dicha variación hace desaparecer la situación de desequilibrio, también se desvanecen las razones que, fundadas en la solidaridad familiar y la equidad, justificaron su fijación inicial. Y, eventualmente, el enriquecimiento indebido que originariamente se buscó evitar podría invertirse dado que se estaría plasmando un enriquecimiento del beneficiario de la compensación a costa del empobrecimiento indebido del obligado justificado en una disparidad o desequilibrio inexistente. En síntesis, mediante esta ponencia, postulo que, -en consonancia con la letra del art. 440 del Código Civil y Comercial-, se admita la posibilidad de revisar, modificar, y extinguir una compensación económica establecida bajo una renta por tiempo determinado o indeterminado si se modifican sustancialmente las circunstancias de desequilibrio que se tuvieron en cuenta al momento de pactarlas o resolverlas judicialmente» ${ }^{14}$.

En otra línea que podríamos adjetivar de intermedia entre la inmutabilidad y la mutabilidad, se ha sostenido que la modificación es posible solo respecto de aquella porción de la renta que atienda a la situación posterior al divorcio, como ser el cuidado de los hijos post ruptura o la imposibilidad de no acceder a un empleo post divorcio:

«Si los escenarios se modifican de manera sustancial (v. gr. la acreedora deja de tener el cuidado de los hijos o se produce una abrupta mejora de la economía, de tal modo que le permita a la beneficiaria obtener en su medio ingresos importantes), el sentido común hace que se justifique en plenitud la modificación o presión de los montos establecidos con miras al futuro, para no generar acuerdos insostenibles desde la óptica de la equidad. (...) lo que corresponde es detraer de la renta todo aquello que fue estimado teniéndose en cuenta el desempeño de la beneficiaria después de producida la ruptura y que en la realidad no han tenido lugar por los nuevos acontecimientos producidos y que no habían sido previstos» ${ }^{15}$.

Por nuestra parte, nos enrolamos en aquella postura que sostiene la inmutabilidad de la compensación económica acordada o fijada judicialmente, pero con una salvedad: el caso de la compensación económica fijada por plazo indeterminado.

14 MAZZINGHI, E. (h.), «Revisión de las compensaciones económicas acordadas por los ex cónyuges o fijadas judicialmente», ponencia presentada por el autor en las Jornadas Nacionales de Derecho Civil La Plata, 28, 29 y 30 de septiembre de 2017. Disponible en <http://jornadasderechocivil.jursoc.unlp.edu.ar/ wp-content/uploads/sites/10/2017/08/Mazzinghi-Esteban-Revision-de-las-compensaciones-economicasComisi\%C3\%B3n-8-2.pdf>. [Consultado el 7/11/2018].

15 MIZRAHI, M. L., Divorcio, alimentos y compensación económica, Buenos Aires (Astrea), 2018, p. 200. 
En este escenario, el carácter netamente equilibrador de patrimonios puede verse diluido, escondiéndose detrás de esta figura un matiz más bien asistencial o alimentario ${ }^{16}$ que podría habilitar su revisión. En esta directriz, se señala:

«Si por hipótesis excepcional la compensación se ha fijado en forma de renta por plazo indeterminado, no podrá descartarse de antemano la posibilidad de revisión. Aunque la ley no habla de "pensión vitalicia" normalmente se devengará y pagará durante un plazo más o menos prolongado que culmina con la muerte del acreedor, a lo largo del cual pueden sobrevenir circunstancias que justifiquen su reformulación $\rangle^{17}$.

Pues si bien es cierto que el carácter de inmutabilidad de la compensación económica se relaciona con su naturaleza jurídica y, en este sentido: «No se trata de alimentos, por lo tanto, ni la mejor situación del deudor o el empeoramiento del acreedor autorizan a modificar el monto adeudado, destinado a restablecer el equilibrio desencadenado por el quiebre de la unión, matrimonial o convivencial» ${ }^{18}$, en el caso de la prestación por plazo

16 Este carácter asistencial de la compensación económica establecida o acordado en plazo indeterminado ha sido destacado en dos proyectos de Ley presentados en la Honorable Cámara de Diputados de la Nación. Así en los fundamentos que acompañan la propuesta de posibilitar la indexación de las obligaciones alimentarias, incluida la compensación económica por plazo indeterminado se sostiene: «sucede que ambos supuestos obligaciones alimentarias y compensación económica por tiempo indeterminado- encierran situaciones de vulnerabilidad por lo cual, se considera pertinente admitir su actualización de conformidad con el principio de solidaridad familiar que rodea a ambas figuras. Asimismo, en consonancia con la obligada perspectiva de género que campea el ordenamiento jurídico nacional, en particular el Código Civil y Comercial según se desprende de sus arts. 1 y 2 , es sabido que en la práctica la mayoría de los conflictos alimentarios involucran a personas menores edad cuyas madres deben afrontar de manera individual el sostenimiento y cuidado de un hijo; o también son las mujeres quienes suelen ser acreedoras de alimentos durante la separación de hecho o después del divorcio, o ser ellas las principales beneficiarias de la nueva figura que incorpora el Código Civil y Comercial, la compensación económica, ya sea tras la ruptura de un matrimonio o el cese de una unión convivencial». (Proyecto de Ley 0794-D-2018, Trámite Parlamentario Nº 8 Fecha: 13/03/2018, Convertibilidad -Ley 23928-. Modificación de los artículos $7^{\circ}$ y 10 , sobre actualizaciones de las deudas de dinero). Misma línea se sigue en otro Proyecto de Ley presentado también en la Honorable Cámara de Diputados de la Nación cuyo objeto es modificar la normativa relativa al derecho a pensión: «esta propuesta legislativa adecúa, en primer lugar, el art. 53 a los términos del sistema de divorcio sin expresión de causa y, conforme el principio de realidad, tiene muy en cuenta una situación fáctica habitual: la separación de hecho como antecedente o situación fáctica en la que acontece el fallecimiento de uno de los cónyuges. De esta forma, si bien el/la viudo/a, es beneficiario del derecho a pensión; en caso de separación de hecho anterior, solo mantendrá el carácter de beneficiario/a, si el causante hubiere tenido a su cargo un deber alimentario a su favor (conf. arts. 432 y 433). Asimismo, acorde con el carácter excepcional del deber alimentario post divorcio establecido en el art. $434 \mathrm{del} \mathrm{CCyC}$, el/la cónyuge divorciado/a, solo será beneficiario del derecho a pensión en caso de percibir alimentos posteriores al divorcio o en el supuesto excepcional de renta por plazo indeterminado en concepto de compensación económica, prevista en el artículo 441 del Código Civil y Comercial». (Proyecto de Ley 2891-D-2017, Trámite Parlamentario N ${ }^{\circ}$ 59 Fecha: 31/05/2017, Sistema integrado de jubilaciones y pensiones -Ley 24241-.Modificación del artículo 53, sobre beneficiarios de la pensión por fallecimiento y adecuación al Código Civil y Comercial de la Nación).

17 MOLINA DE JUAN, M., Compensación Económica, cit., p. 295.

18 PELLEGRINI, M. V., «Compensaciones económicas: formas de cumplimiento, cuestiones posteriores a su fijación y posible superposición en los casos de uniones que cesan por matrimonio», Derecho de Familia. Revista 
indeterminado la naturaleza o finalidad del instituto si bien sigue siendo el compensar el desequilibrio, su prolongación de forma indefinida da cuenta de una mayor vulnerabilidad o necesidad.

\section{Caducidad y Compensación Económica}

Como adelantáramos, la compensación económica puede ser el resultado de un convenio entre cónyuges o, con posterioridad al divorcio, ser decidida por el juez a petición de parte interesada. En este último supuesto, cobra relevancia el instituto de la caducidad. El artículo 442 del CCyC establece que la acción para reclamar la compensación económica caduca a los seis meses de haberse dictado la sentencia de divorcio.

Sobre este punto han surgido dos discusiones hermenéuticas, la primera, desde cuándo comienza a contarse el plazo de seis meses y, la segunda, si la caducidad de la compensación económica es materia dispositiva o puede ser declarada de oficio por el juez.

En relación con la primera arista tres son las interpretaciones que se han dado en la doctrina y jurisprudencia: a) una que sostiene que el plazo de caducidad comienza a contabilizarse desde el día del dictado de la sentencia de divorcio, b) otra que afirma que el comienzo del cómputo del plazo opera desde la notificación de la sentencia de divorcio al interesado y c) una última, a la cual adherimos, que interpreta que el plazo se debe comenzar a computar a partir de que la sentencia ha quedado firme, es decir, que haya adquirido estado de cosa juzgada.

Como ejemplo de la primera tesitura, podemos citar lo resuelto por la Cámara Nacional de Apelaciones en lo Civil, Sala I, el pasado 17/04/2018. En el marco de una apelación interpuesta por la actora contra la resolución de primera instancia que hizo lugar a la caducidad de la acción de compensación económica alegada por el demandado, por haber transcurrido el plazo de los seis meses previsto por el art. 442 del CCyC desde el dictado de la sentencia de divorcio, la Alzada confirma la caducidad enrolándose en una interpretación literal no finalista de la norma.

«El art. 442 del Cód. Civ. y Com. de la Nación es claro en cuanto a que el plazo en cuestión debe computarse desde el dictado de la sentencia de divorcio, y no así desde su notificación a los eventuales interesados y tampoco desde que aquella adquiera firmeza siendo aplicable el principio general en materia de interpretación jurídica que, donde la ley no distingue, nosotros no debemos distinguir y en el caso la disposición en estudio es contundente en cuanto al momento en que debe comenzar a computarse el término en cuestión: desde el dictado de la sentencia de divorcio».

\footnotetext{
Interdisciplinaria de Doctrina y Jurisprudencia, núm. 78, 2017. Disponible en <http://www.pensamientocivil. com.ar/doctrina/3732-dos-preguntas-inquietantes-compensacion-economica $>$. [Consultado el 7/11/2018].
} 
Agregando:

«De manera que si la intención de alguno de los esposos es la de iniciar un reclamo de compensación económica y la ley señala que el plazo de caducidad es breve y que comenzará a correr desde el dictado de la sentencia que decrete el divorcio vincular por aplicación del art. 442 in fine del Cód. Civ. y Com. de la Nación, el interesado deberá estar atento al trámite y ejercer su derecho en la oportunidad procesal que establece el art. 442 del Cód. Civ. y Com. de la Nación. Para tal afirmación considero, asimismo, que el art. 2 del Título Preliminar del mismo cuerpo legal nos da la pauta para interpretar la ley y dice que debo tener en cuenta sus palabras y sus finalidades, la que en este caso es la de resolver todos los conflictos que genera el divorcio en un tiempo cercano al dictado de la sentencia y, además, otro principio rector dice que los derechos deben ser ejercidos de buena fe» ${ }^{19}$.

Enrolándose en la segunda posición, el Juzgado Nacional Civil núm. 4 en fecha 26/02/2018 rechazó el planteo del demandado tendiente a que se declare la caducidad de la acción por compensación económica, por entender que ya habían transcurrido más de seis meses desde el dictado de la sentencia de divorcio. Para así resolver, sostuvo:

«En primer lugar, debo destacar que al señalar la norma que la acción "caduca" a los seis meses, no caben dudas de que se trata de un plazo de caducidad regido en principio por lo que disponen los artículos 2566 a 2572 del Cód. Civ. y Com. de la Nación. En segundo lugar, también corresponde señalar que, si bien de una interpretación literal de la norma se desprendería que el comienzo del cómputo del plazo de caducidad coincide con la fecha de la sentencia de divorcio, entiendo que una interpretación sistemática y armónica de dicho precepto, tal como manda realizar el artículo 2 del Cód. Civ. y Com. de la Nación, en concordancia con principios elementales del derecho procesal, impone una solución diversa, pues todo acto procesal (tal la sentencia) se integra necesariamente con su notificación (conf. Palacio, Lino E. - Alvarado Velloso, Adolfo, Cód. Proc. Civ. y Com. de la Nación Comentado, Rubinzal-Culzoni, 1989, T. 4, p. 191) por lo que, a mi modo de ver, dicha norma sustancial, debe necesariamente integrarse con los principios y efectos propios de los actos procesales, entendiéndose que el comienzo del cómputo del plazo opera desde su notificación al interesado» ${ }^{20}$.

Por último, como ejemplo de la tercera línea hermenéutica, podemos citar el caso resuelto por el Juzgado Nacional en lo Civil Nro. 56 el 12/07/2018 que fuera confirmado

\footnotetext{
19 Cámara Nacional de Apelaciones en lo Civil, Sala I, 17/04/2018, «V. L., M. F. c. B., G. M. s/ acción compensación económica», La Ley, AR/JUR/23936/2018.

20 Juzgado Nacional de 1a Instancia en lo Civil núm. 4, 26/02/2018, «B., D. M. c. O., C. P. s/ fijación de compensación económica - arts. 441 y 442 CCCN», La Ley, AR/JUR/37171/2018.
} 
por la Cámara Nacional de Apelaciones en lo Civil, Sala C, el pasado 20/09/2018 ${ }^{21}$. En esta oportunidad, la jueza de primera instancia, con criterio que compartimos, rechaza el planteo de caducidad sosteniendo que: «Más allá de la literalidad de la norma que remite al dictado de la sentencia, desde un primer momento parte de la doctrina entendió que el plazo debe computarse desde la fecha en que la sentencia queda firme (Conf. Veloso, Sandra F., en Rivera, Julio C.- Medina, Graciela, Código Civil y Comercial de la Nación. Comentado, Ed. La Ley, t. II, p. 89; Solari, Néstor E., «Sobre el carácter renunciable de la prestación compensatoria», DFyP, julio de 2014, Ed. LL, p. 10; Morano, Estela- Eisen, Lucía S.- Rato, María Clara, «La compensación económica: presupuestos de procedencia», LL Online: AP/ DOC/245/2017)». Agregando: «Es así que se concluye, que, si no hay una sentencia firme, no puede haber divorcio; y si no se ha decretado el divorcio, ningún derecho a compensación puede exigirse. De allí, que el plazo para reclamar la compensación económica no podría haber comenzado a correr con anterioridad a que la decisión judicial adquiriera firmeza» ${ }^{22}$.

Consideramos que esta tercera tesitura es la más justa y equilibrada pues extiende el plazo para peticionar una compensación económica y, de esta forma, amplía la legitimación activa y la posibilidad -comprobados los requisitos sustantivos de procedencia de la compensación económica- de que mayor número de personas puedan contar con recursos económicos necesarios para encarar un plan de vida autónomo de su expareja.

Por otra parte, dentro del cruce entre caducidad y compensación económica derivada del divorcio, se han planteado diferencias doctrinarias que se relaciona más directamente con la matriz interpretativa de presente trabajo -la autonomía y sus límites-; nos referimos a la posibilidad de la declaración de oficio de la caducidad de la compensación económica.

En este sentido, en respecto del principio de autonomía, una parte de la doctrina ${ }^{23}$ interpreta que la caducidad no puede ser declarada de oficio por el juez por ser la compensación económica materia disponible para las partes. Así se ha afirmado:

«Los Supuestos de Caducidad reconocidos por el Código Civil y Comercial solo autorizan su declaración de oficio por el juez, cuando están establecidos por la ley y son materia sustraída a la disposición de las partes (art. 2572 del CCyC). No es el caso de la compensación económica, que es un derecho disponible, por lo tanto -de igual modo que no procede fijarlas de oficio- tampoco es posible declarar su caducidad sino ha sido peticionada por la parte demandada $\rangle^{24}$.

21 Cámara Nacional de Apelaciones en lo Civil, Sala C, 20/09/2018, «V. M. M. c/ M., G. E. s/ fijación de compensación económica - arts. 441 y 442 CCCN», inédito.

22 Juzgado Nacional Civil núm. 56, 12/07/2018, «V. M. M. c/ M., G. E. s/ fijación de compensación económica - arts. 441 y 442 CCCN», inédito.

23 Ver, entre otros, MIZRAHI, M. L., «Compensación Económica. Pautas, Cálculo, Mutabilidad, Acuerdos y Caducidad», La Ley, 06/08/2018, 1, p. 721; KIELMANOVICH, J. L., «¿Caducidad de oficio de la acción de compensación económica?», La Ley, 03/05/2017, 1, p. 1068; SOLARI, N. E., «El plazo de caducidad en la compensación económica», La Ley, 03/10/2017, 1, p. 1037.

24 MOLINA DE JUAN, M., Compensación económica, cit., p. 108. 
En sentido contrario, existen voces que, si bien no discuten que la compensación económica es materia disponible para las partes, señalan que fue intención del legislador que los conflictos derivados del divorcio sean rápidamente resueltos. Así se ha sostenido que:

«Existe entonces un marcado interés público en que los conflictos de familia no se prolonguen indefinidamente, sino que sean dirimidos sin gran dilación». Agregando que: «siendo que existe un interés público, las partes no pueden disponer respecto del breve plazo de caducidad previsto por ley. En consecuencia, encontrándose la materia (léase caducidad) sustraída a la disponibilidad de las partes, el juez debe declarar de oficio la caducidad cuando esta hubiese operado $»^{25}$.

Si bien compartimos que el legislador ha previsto un plazo breve de caducidad -seis meses- con el fin de que los efectos del divorcio se resuelvan de forma concentrada y sin mayores dilaciones, ello no debilita el carácter dispositivo de la compensación económica $\mathrm{y}$, menos aún, la preferencia de la legislación vigente por toda solución que provenga de un acuerdo de partes por sobre la imposición heterónoma, en este caso, la posible declaración de oficio.

\section{COMPENSACIÓN ECONÓMICAY CESE DE LAUNIÓN CONVIVENCIAL}

\section{Consideraciones previas}

El Código Civil y Comercial define a la unión convivencial como una unión basada en relaciones afectivas de carácter singular, pública, notoria, estable y permanente de dos personas que conviven y comparten un proyecto de vida común, sean del mismo o de diferente sexo (art. 509 del CCyC).

Asimismo, exige una serie de requisitos a ser cumplidos para que proceda el reconocimiento de ciertos efectos jurídicos: mayoría de edad, no estar unidos por vínculos de parentesco, no estar casados o en otra unión convivencial y mantener la convivencia por un mínimo de dos años (art. 510 CCyC), no se exige el registro de la unión como modo de constitución. Es decir, la registración es posible y se prevé, pero solo a los fines de facilitar la prueba de la unión (arts. 511 y 512 del CCyC) aunque las parejas registradas tengan un plus de reconocimiento frente a terceros respecto de la protección de la vivienda familiar ${ }^{26}$.

25 BECCAR VARELA, A. y BUSTAMANTE, E., «La caducidad del derecho a la compensación económica», La Ley, 12/06/2018, 1, p. 927.

26 Artículo 522: Protección de la vivienda familiar. Si la unión convivencial ha sido inscripta, ninguno de los convivientes puede, sin el asentimiento del otro, disponer de los derechos sobre la vivienda familiar, ni de los muebles indispensables de esta, ni transportarlos fuera de la vivienda. El juez puede autorizar la disposición del bien si es prescindible y el interés familiar no resulta comprometido. Si no media esa autorización, el que no ha dado su asentimiento puede demandar la nulidad del acto dentro del plazo de caducidad de seis meses de haberlo conocido, y siempre que continuase la convivencia. La vivienda familiar no puede ser ejecutada 
Una vez determinados el concepto, requisitos y fines de la registración, el Código Civil y Comercial introduce el «principio estrella» que regula las relaciones entre adultos en este tipo de organización familiar: la autonomía de la voluntad expresada en la posibilidad de pactar, estableciendo, desde ya, razones de orden público (art. 515) que limitan su contenido, más un piso mínimo de derechos insoslayable -haya o no haya pacto o, incluso, contra pacto (arts. 519/522)-. Los pactos tendrán validez, entre partes, desde el momento de su celebración y, frente a terceros, desde el momento de su registración. El cese de la convivencia extingue, entre las partes, de pleno derecho los efectos hacia el futuro y, respecto de terceros, se exige la constancia de ruptura en el registro/s para que le sea oponible (arts. 516 y 517 del CCyC).

En cuanto al quiebre o ruptura la pareja, conforme lo establece el art. 523 del CCyC, las causales de cese de la unión convivencial son las siguientes: a) la muerte de uno de los convivientes; b) la sentencia firme de ausencia con presunción de fallecimiento de uno de los convivientes; c) el matrimonio o nueva unión convivencial de uno de sus miembros; d) el matrimonio de los convivientes; e) el mutuo acuerdo; f) la voluntad unilateral de alguno de los convivientes notificada fehacientemente al otro y g) el cese de la convivencia mantenida. La interrupción de la convivencia no implica su cese si obedece a motivos laborales u otros similares, siempre que permanezca la voluntad de vida en común.

Los efectos una vez cesada la unión convivencial, solo aplicables en caso de inexistencia de pacto en contrario son los siguientes: a) compensación económica, arts. 524 y 525, b) atribución de la vivienda familiar, art. 526 y c) atribución de la vivienda por fallecimiento de uno de los convivientes, art. 527 y d) distribución de bienes, art. $528^{27}$.

Concentrándonos en nuestro objeto de estudio, la compensación económica, como sintetizamos en nuestra introducción, tres son las condiciones fácticas que justifican la procedencia de un reclamo compensatorio entre los integrantes de la unión -las mismas rigen para el caso de divorcio entre cónyuges (art. $441 \mathrm{CCyC}$ )-: a) que se produzca un desequilibrio manifiesto entre un conviviente y el otro; b) que ese desequilibrio implique un empeoramiento de su situación y c) que tenga por causa adecuada la convivencia y su ruptura ${ }^{28}$.

De esta forma, salvo pacto en contrario de los convivientes, el cese de la unión traerá como uno de sus efectos, la posibilidad de que se reclame una compensación económica pero su virtualidad estará atada al cumplimento de estos requisitos de procedencia. En otras

por deudas contraídas después de la inscripción de la unión convivencial, excepto que hayan sido contraídas por ambos convivientes o por uno de ellos con el asentimiento del otro.

27 DE LA TORRE, N., «Algunas consideraciones en torno a la regulación de las uniones convivenciales. El difícil equilibrio entre el principio de autonomía y la solidaridad familiar», en GRAHAM, M. y HERRERA, M. (dirs.), Derecho de las Familias, Infancia y Adolescencia. Una mirada crítica y contemporánea, 1. a ed., Buenos Aires (Infojus), 2014, pp. 325-348.

28 PELLEGRINI, M. V., «Comentario al artículo 441 del CCyC», en KEMLEMAJER DE CARLUCCI, A.; HERRERA, M. y LLOVERAS, N. (dirs.), Tratado de Derecho de Familia, según código Civil y comercial 2014, Tomo I, Santa Fe (Rubinzal Culzoni), 2014, p. 424. 
palabras, la compensación es un efecto post cese de la unión, pero no todo cese implicará necesariamente su nacimiento.

Por otra parte, cabe destacar que el artículo 524 del Código Civil y Comercial confiere la posibilidad de reclamar la compensación económica una vez cesada la convivencia, especificando el último párrafo que la acción para reclamar la compensación caduca a los seis meses de haberse producido cualquiera de las causas de finalización de la convivencia enumeradas en el art. 523.

De esta forma, a diferencia de lo que ocurre en el caso del matrimonio donde la compensación económica está pensada solo como un efecto del divorcio (art. 441 del CCyC) y no para el resto de las causales de disolución (muerte de los cónyuges y sentencia firme de ausencia con presunción de fallecimiento, entre otras, -art. 435 del CCyC-), en el caso de las uniones la compensación procede cualquiera sea la causal del cese, incluidos los supuestos de muerte y sentencia firme de ausencia con presunción de fallecimiento de uno de los integrantes de la unión.

En este sentido, en las uniones convivenciales, ante la ocurrencia de la muerte de uno de los convivientes o la ausencia con presunción de fallecimiento, el conviviente supérstite se presentará en el juicio sucesorio -dentro del plazo de caducidad de seis meses que establece el artículo 525- y pedirá la compensación a los herederos del causante, siendo viable el reclamo siempre que se cumplan los requisitos de desequilibrio manifiesto y empeoramiento de la situación económica con causa adecuada en la unión y su cese y no exista pacto en contrario de los convivientes.

Los fundamentos de esta regulación diferenciada para el caso del matrimonio y para las uniones convivenciales surgen de una lectura sistémica de los efectos previstos en ambos institutos. A diferencia de lo que ocurre en el matrimonio, los convivientes no son herederos legitimarios entre sí, por tanto de existir una situación de empeoramiento de la situación económica del conviviente supérstite esté no podrá verse apaciguado a través de los bienes que recibirá por herencia ni, incluso, por la disolución de un régimen de comunidad de ganancias que si puede darse en el caso de algunos matrimonios que no hayan optado por el régimen de separación de bienes o por la habitación vitalicia y gratuita prevista en el artículo 2383 del CCyC.

\section{Dos pronunciamientos jurisprudenciales de interés}

En este subapartado nos interesa compartir con el lector/a dos recientes sentencias a modo de disparador para seguir repensando, por un lado, la tensión siempre latente entre orden público y autonomía de la voluntad en las relaciones de familia, y, por otro lado, el diálogo constante entre normativa legal y normativa supralegal, en otras palabras, la re- 
lectura contemporánea del orden público desde la obligada visión de derechos humanos, incluida en ella la perspectiva de género.

En primer lugar, resulta de interés traer a colación una sentencia de fecha 10/08/2017 dictada por el Juzgado Civil y Comercial núm. 1 de Oberá, Misiones, Argentina ${ }^{29}$ que sirve para ilustrar las características particulares de la compensación económica en la unión convivencial y, también, para seguir analizando el cruce entre autonomía de la voluntad y orden público en las relaciones de familia en sentido amplio. Veamos.

Se trata de una conviviente supérstite (convivencia de veinte años, con un hijo en común) que, ante el cese de la convivencia por muerte de su pareja, el Sr. P., se presenta en su sucesorio y promueve incidente de compensación económica contra los herederos denunciados en el expediente de sucesorio respectivo (hijo en común e hijos de un matrimonio anterior).

Solicita la declaración de inconstitucionalidad del actual art. 510 del CCyC, inc. d (impedimento de ligamen), en tanto el causante nunca se había divorciado de su esposa pese a haberse separado de hecho hace más de veinte años. Cuenta que previo a comenzar a convivir con el causante la actora trabajaba como modista y solventaba sola todos sus gastos, pero cuando nace el hijo en común, renuncia a la vida que antes tenía y se dedica a los quehaceres del hogar, a su hijo y su pareja.

En este marco, antes de analizar las condiciones de procedencia de la compensación económica, el juez primero debe decidir si corresponde o no declarar inconstitucional el requisito de inexistencia de impedimento de ligamen para acceder al reconocimiento de los efectos jurídicos previstos para las uniones convivenciales.

En ese orden, el juez sostiene: «Las políticas estatales de captación normativa no se apartan, o más bien tienen como punto de partida el Derecho Internacional respecto a los Derechos Humanos. Esto se debe a la necesidad de que no se dé por supuesta la vigencia social de un modelo único y eterno de familia (el nuclear patriarcal)». Agregando:

«No se considera correcto que pudieran invocarse motivos religiosos, ni morales ni convencionales, ni jurídicos para estigmatizar un acto que no es en sí mismo irreligioso, ni inmoral, ni opuesto a las buenas costumbres, ni antijurídico. La relación comprometida: continua, prolongada con neta vocación de permanencia no puede resultar indiferente a la comunidad porque de hecho posee aptitud para generar secuelas tan notables como las provenientes de la relación matrimonial».

29 Juzgado Civil y Comercial núm. 1, Oberá, Misiones, 10/08/2017, «Expte. núm. 11570/2016 BIS 1/16 D. S. R. C. C/Sucesores de P. H. N. S/Incidente, inédito. (Sentencia aclaratoria 6/10/2017), inédito. 
En suma:

«En el caso concreto, el excluir de la clasificación como unión convivencial con sus respectivas consecuencias jurídicas a la presente, no solo desconoce la verdad real, es decir, la situación de hecho realmente producida; sino que entiendo se realiza una valoración discriminatoria, que castiga la decisión de las partes por el modelo de familia elegido, ya que como se manifestara precedentemente, desproteger a la parte, desconocerle la decisión de elección de tal o cual forma de familia es ir en contra no solo de la intención de la normativa, sino además de la propia Constitución Nacional».

Una vez declarada la inconstitucionalidad del inc. d. del art. 523 del CCyC, el juez hace lugar al reclamo y fija una compensación económica otorgando a la conviviente supérstite la atribución del usufructo de la vivienda sede del hogar convivencial por el término de diecisiete años, en concepto de renta, aclarando que dicho plazo se computará a partir de la fecha del cese de la convivencia; es decir, de la fecha del fallecimiento del causante.

Con relación a la forma de pago fijada en la sentencia, cabe destacar, que el texto civil y comercial argentino, da una amplia libertad de formas pues permite, tanto en el caso del divorcio como en el del cese de la convivencia, el pago mediante una suma de dinero, con el usufructo de determinados bienes o de cualquier otro modo que acuerden las partes o en su defecto decida el juez (arts. 441 y 523 del CCyC).

El segundo precedente jurisprudencial que cabe traer a colación fue resuelto en fecha 6/09/2018 por la Cámara de Apelaciones Civil, Comercial, Laboral y de Minería, provincia de Neuquén, Argentina ${ }^{30}$. En esta oportunidad, el conflicto está centrado en el cómputo del plazo de caducidad; es decir, ¿desde cuándo corre el plazo de seis meses que establece el art. 524 del CCyC?

La plataforma fáctica, sucintamente, es la siguiente. El 6/02/2017 la Sra. M.F.C. se retira junto a su hija de la vivienda familiar que compartía con su entonces conviviente, el Sr. C.J.L., y sus dos hijos comunes. Ello a raíz de una serie de acontecimientos violentos ejercidos por el Sr. C.J.L. contra la Sra. M.F.C. los que, a su vez, dieron lugar a una denuncia por violencia familiar. El 20/09/2017 la Sra. M.F.C. inicia una acción judicial peticionando la fijación de una compensación económica. Señala que durante la vida de pareja acordaron que ella no trabajara para poder cuidar a los hijos, por lo cual se encuentra desempleada y con pocas expectativas de encontrar un empleo por su inexperiencia.

Al contestar demanda, el Sr. C.J.L., opone falta de legitimación por haber operado el plazo de caducidad de la acción en los términos del art. 525 del CCyC, en fecha 06/08/2017. En este contexto, la Sra. M.F.C. plantea la inconstitucionalidad del plazo de caducidad.

30 Cámara de Apelaciones en lo Civil, Comercial, Laboral y Minería de Neuquén Sala I, 06/07/2018, «M. F. C. c. C. J. L. s/ compensación económica», RCCyC, 2018 (octubre), 91, La Ley: AR/JUR/39399/2018. 
El tribunal de primera instancia hace lugar a la defensa opuesta y rechaza la demanda, declarando la caducidad de la acción para reclamar la compensación económica. La actora apela y el Tribunal de Alzada revoca la sentencia, rechazando la defensa opuesta por el demandado y ordenando que continúe el trámite en la instancia de grado según su estado. Para así resolver, la Cámara tuvo en especial consideración dos aristas: a) la situación de vulnerabilidad en que se encontraba la señora y la obligación de analizar el caso desde la obligada perspectiva de género y b) las Reglas de Brasilia sobre Acceso a la Justicia de las personas en condición de vulnerabilidad.

En relación con el primer punto (a) sostuvo: «no cabe duda de que el plazo de caducidad debe ser próximo al cese de la convivencia, porque contribuye a evitar o paliar lo antes posible el perjuicio patrimonial del solicitante, logrando así una separación limpia e integral que intenta resolver los desajustes económicos propios de toda crisis de pareja lo más pronto posible». No obstante: «[e]l cuadro de situación nos permite concluir que la Sra. M. se retiró de la vivienda como consecuencia del episodio denunciado, en un estado de confusión y vulnerabilidad, y a fin de proteger su propia integridad psico-física y la de su hija. Tal conducta, claramente, no responde a una decisión personal profunda y meditada sobre el cese de la convivencia». Agregando:

«Desde perspectiva, dada la especial situación de violencia que se deriva de los hechos denunciados, la inestabilidad del grupo familiar en esos momentos y el estado de vulnerabilidad que atravesaba en dicha ocasión la peticionante, concluimos que el cómputo del plazo de caducidad para el ejercicio de esta acción no pudo iniciar el mismo 06/02/2017. A ello se suma el breve lapso de tiempo transcurrido entre el 6/08/2017 -6 meses- desde el 06/02/2017-y el 20/09/2017fecha de interposición de la acción-»).

En cuanto al acceso a la justicia (b), la Alzada destacó la necesidad, agregaríamos, la obligación, de interpretar las normas del $\mathrm{CCyC}$, en materia de caducidad, en un diálogo de fuentes:

«Que no puede desprenderse de las directivas dadas en las Reglas de Brasilia sobre Acceso a la Justicia de las Personas en Condición de Vulnerabilidad, en tanto establece en su Sección 2da. 1., que se consideran en condición de vulnerabilidad, aquellas personas que, por razón de su edad, género, estado físico o mental, o por circunstancias sociales, económicas, étnicas y/o culturales, encuentran especiales dificultades para ejercitar con plenitud ante el sistema de justicia los derechos reconocidos por el ordenamiento jurídico». 
En suma:

«Haciendo una interpretación armónica de la normativa protectoria referida y el régimen aplicable a las compensaciones económicas por finalización de la convivencia, corresponde hacer lugar al recurso de apelación deducido por la actora, en tanto, en el caso y frente a las circunstancias que rodearon la separación, la interpretación efectuada en la instancia de origen, conduce a un resultado que se desentiende de la protección a una mujer en situación de violencia, con separación de los postulados protectorios supralegales»».

De esta forma, con criterio que compartimos, evaluando la situación de vulnerabilidad de la mujer debido a la violencia de género sufrida, el tribunal de alzada revoca la decisión meramente formalista de primera instancia y habilita el reclamo de compensación económica en favor de la mujer.

El precedente citado es útil para reflexionar sobre la posibilidad de una reforma legislativa en torno al plazo de caducidad de la compensación económica en el caso de las

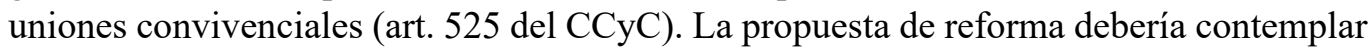
una respuesta adecuada a los casos signados por violencia de género y, más genéricamente, debería plantear una extensión del plazo de caducidad teniendo en consideración que hoy el plazo previsto por la norma comienza a computarse desde el inicio de la separación de las partes sin que ellas hayan accedido a un asesoramiento jurídico previo como si sucede en el caso del divorcio.

Los fallos sintetizados resuelven los casos teniendo en consideración no solo las palabras de la ley y su finalidad sino, principalmente, los tratados de derechos humanos. Buenos ejemplos del cumplimiento del deber de resolver mediante decisiones razonablemente fundadas (art. $3 \mathrm{CCyC}$ ) y de asegurar el acceso a una herramienta como la compensación económica que permite contar con recursos económicos mínimos para poder planificar y ejecutar un plan de vida individual e independiente de su expareja.

\section{Debate: ¿se puede renunciar anticipadamente a la compensación económica?}

Antes de pasar a analizar el debate en torno a la posibilidad de renunciar en forma anticipada a la compensación económica en el caso de las uniones convivenciales, conviene recordar cuáles son los límites impuestos por el legislador a la facultad de celebrar pactos entre convivientes.

En primer lugar, los pactos de convivencia no pueden contrariar lo que en doctrina se denomina «piso mínimo obligatorio», a saber: a) la asistencia durante la convivencia, b) la contribución a los gastos del hogar c) la responsabilidad solidaria frente a terceros y d) 
la protección de la vivienda, en este caso, solo aplicable para las uniones convivenciales registradas.

En segundo término, conforme lo establece el art. 515 del CCyC, los pactos de convivencia no pueden ser contrarios al orden público, ni al principio de igualdad de los convivientes, ni afectar los derechos fundamentales de cualquiera de los integrantes de la unión convivencial.

En este marco, al no conformar la compensación económica el piso mínimo obligatorio e inderogable para las partes, el interrogante con relación a la renuncia anticipada a la compensación económica se concentra en la naturaleza de esta figura y en la interpretación del art. 515.

Aquellos que sostienen que es posible renunciar anticipadamente a la compensación económica afirman que es posible renunciar a prerrogativas que aún no han nacido y que al no conformar el piso mínimo obligatorio es viable la exclusión voluntaria de una ley dispositiva $^{31}$.

Esta posición es la que ha prevalecido en las XXXIII Jornada Notarial Argentina celebradas en la Ciudad de Bariloche, provincia de Río Negro, a fines de septiembre de $2018^{32}$. En las conclusiones del tema III, «Uniones Convivenciales», se sostuvo:

«La compensación económica contemplada en los arts. 524 y $525 \mathrm{CCCN}$ procede ante cualquier causa de cese de la unión convivencial de los contemplados en el art. $523 \mathrm{CCCN}$ y es acumulable a la acción por enriquecimiento sin causa, a la acción por interposición de personas u a otras acciones que pudieren corresponder en los términos del art. $528 \mathrm{CCCN}$. El usufructo de bienes determinados puede extenderse por un plazo mayor a la duración de la unión convivencial. Cuando los convivientes contraen nupcias entre sí, el plazo de caducidad de la compensación comienza al disolverse el matrimonio, debiendo entenderse la "finalización de la convivencia" del art. 528 CCCN in fine, como cese de proyecto común. Por ende, se tomará todo el período de duración de la unión convivencial y el matrimonio para la determinación de la admisibilidad y el quantum de la compensación. En el marco del pacto de convivencia, es válida la renuncia anticipada a la compensación económica, por entenderse que se trata de un derecho disponible y sin perjuicio de que sea revisable ante un cambio de las circunstancias».

En cambio, aquellos que se oponen a la renuncia anticipada destacan el hecho de que esta podría violentar el principio de igualdad entre los convivientes y consolidar o a agravar las relaciones desiguales de poder que se dan entre los miembros de una pareja a raíz de

\footnotetext{
31 MOLINA DE JUAN, M., Compensación Económica, cit., pp. 279 y ss.

32 Información disponible en http://colegionotarialrn.org/rionegro/xxxiii-jornada-notarial-argentina/, [Consultado el 8/11/2018].
} 
los roles estereotipados que aún persisten en nuestra sociedad. Así se ha afirmado que, «se trata de no convertir este instituto en ilusorio, por las inevitables posiciones dominantes - de orden material o sentimental- que un cónyuge o un conviviente, de un modo u otro, pueda llegar a ejercer sobre el otro, y que a la postre habiliten a burlar la normativa en análisis $)^{33}$.

Como dijéramos en otra oportunidad, la cuestión se relaciona con la naturaleza jurídica de la compensación económica, tema que no resulta pacífico en doctrina, inclinándose por reconocer su naturaleza sui géneris, con contenido patrimonial, pero a la vez de protección asistencial. Dado su carácter de derecho deber de contenido patrimonial, es más factible admitir su renuncia anticipada. Pero tratándose de una herramienta legal de protección a la parte más vulnerable de la relación, se trataría de un ámbito de indisponibilidad, ajeno a la autonomía de la voluntad en el cual la perspectiva de género resultará crucial ${ }^{34}$.

Por último, cabe destacar que, en el marco de este debate doctrinario, el 8/03/2018, se presentó en la Honorable Cámara de Diputados de la Nación un proyecto de ley que tiene por objeto modificar el artículo 513 del CCyC, estableciendo un último párrafo que reza: «[q]ueda expresamente prohibida y es de ningún valor la renuncia anticipada a la compensación económica formulada por uno o ambos convivientes al momento de celebrar el pacto de convivencia» ${ }^{35}$. Al momento de escribir estas líneas el proyecto aún no ha recibido tratamiento legislativo.

\section{BREVES PALABRAS DE CIERRE}

Como toda novedad, la incorporación de la compensación económica al derecho argentino ha abierto una serie de debates que lejos están de concluir y que se engloban en una disputa aun mayor respecto a los límites de la autonomía de la voluntad en las relaciones de familia.

Quizá las palabras de uno de los más reconocidos filósofos del derecho argentino nos puedan servir de guía para sostener el porqué de ciertos límites en relación a la figura de la compensación económica:

«Existe un estrecho vínculo entre autonomía personal e independencia económica, o cuanto menos, la posibilidad de control individual de ciertos recursos económicos, principalmente los bienes de uso personal. Porque sin ese control individual de recursos es imposible la elección y materialización de planes de vida constitutivos de la autonomía de la persona, ello así pues la capacidad de elegir

\footnotetext{
33 MIZRAHI, M. L., Divorcio, alimentos y compensación económica, cit. 195.

34 DE LA TORRE, N. y PELLEGRINI, M. V., «Uniones Convivenciales», en KEMLEMAJER DE CARLUCCI, A.; HERRERA, M. y LLOVERAS, N. (dirs.), Tratado de Derecho de Familia, según código Civil y comercial 2014, Tomo V-A, Santa Fe (Rubinzal Culzoni), 2014, p. 474.

35 Proyecto de Ley 0558-D-2018, Trámite Parlamentario núm. 5. Fecha:8/03/2018. Código Civil y Comercial de la Nación - Ley 26994 - . Modificación del artículo 513, sobre autonomía de la voluntad de los convivientes.
} 
y materializar planes de vida requiere no solo ciertas condiciones psicológicas y físicas de los individuos, sino también recursos externos que potencien las primeras condiciones y permitan la plasmación de las preferencias de los individuos en el mundo exterior. Es que los recursos económicos son indispensables prácticamente en todos los proyectos vitales $\rangle^{36}$.

Al ser la compensación económica una herramienta que permite acceder a estos recursos económicos, para asegurar la autonomía futura -post divorcio o post cese de la unión convivencial- consideramos justificados los límites a la autonomía de la voluntad planteados por el legislador, así como aquellas interpretaciones de la judicatura y/o doctrina que tienen por fin asegurar el acceso a este instituto.

Por esta razón, en el marco de la compensación económica como efecto del divorcio, nos hemos enrolado en aquella postura que sostiene la inmutabilidad de las compensaciones económicas acordadas y homologadas por el juez o las fijadas judicialmente, con excepción del caso de la compensación establecida por plazo indeterminado que sostenemos puede ser revisada. Asimismo, en relación con la caducidad, hemos compartido la línea interpretativa que afirma que el plazo de caducidad - seis meses- comienza a computarse una vez que la sentencia de divorcio se encuentra firme, rechazando la posibilidad de que la caducidad sea declarada de oficio por el juez. En la misma línea, se encuadra nuestro posicionamiento contrario a la posibilidad de renunciar anticipadamente a la compensación económica en el marco de una unión convivencial.

En suma, los límites a la autonomía de la voluntad analizados encuentran su justificación en la preservación y protección de la autonomía personal. En otras palabras, fortalecen la capacidad de las personas, en especial de las mujeres, para actuar autónomamente una vez producida la ruptura de pareja o matrimonio.

\section{BIBLIOGRAFÍA}

BECCAR VARELA, A. y BUSTAMANTE, E., «La caducidad del derecho a la compensación económica», La Ley, 12/06/2018-C, 1, p. 927.

BORILLO, D., «La contractualización de los vínculos de familia», Derecho de Familia. Revista Interdisciplinaria de Doctrina y Jurisprudencia, núm. 79, 2017. Disponible en $<$ https://hal.archives-ouvertes.fr/hal-01528614/document $>$. [Consultado el 7/11/2018].

DE LA TORRE, N., «Algunas consideraciones en torno a la regulación de las uniones convivenciales. El difícil equilibrio entre el principio de autonomía y la solidari-

\footnotetext{
36 NINO, C., Fundamentos de Derecho Constitucional. Análisis Filosófico, jurídico y politológico de la práctica constitucional, Buenos Aires (Astrea), 1992, p. 363.
} 
dad familiar», en Derecho de las Familias, Infancia y Adolescencia. Una mirada crítica y contemporánea, 1. ${ }^{a}$ ed., Buenos Aires (Infojus), 2014, pp. 325-348.

DE LA TORRE, N. y PELLEGRINI, M. V., «Uniones Convivenciales», en KEMELMAJER DE CARLUCCI, A.; HERRERA, M. y LLOVERAS, N. (dirs.), Tratado de Derecho de Familia, Tomo V-A, Santa Fe (Rubinzal Culzoni), pp. 385-505.

DUPRAT, C., «Comentario al artículo 439», en KEMELMAJER DE CARLUCCI, A.; HERRERA, M. y LLOVERAS, N. (dirs.), Tratado de Derecho de Familia. Según el Código Civil y Comercial de 2014, Tomo I, Santa Fe (Rubinzal Culzoni), 2014, pp. 401-404.

DUPRAT, C., «Comentario al artículo 440», en KEMELMAJER DE CARLUCCI, A.; HERRERA, M. y LLOVERAS, N. (dirs.), Tratado de Derecho de Familia. Según el Código Civil y Comercial de 2014, Tomo I, Santa Fe (Rubinzal Culzoni), 2014, pp. 404-412.

GARGARELLA, R, «Constitucionalismo y privacidad», en GARGARELLA, R. (coord.), Teoría y Crítica del Derecho Constitucional, Tomo II, Buenos Aires (Abeledo Perrot), 2010, pp. 779-796.

GIL DOMÍNGUEZ, A.; FAMÁ, M. V. y HERRERA, M., Derecho Constitucional de Familia, Buenos Aires (Ediar), 2006.

KEMELMAJER DE CARLUCCI, A. y HERRERA, M., «Convenio regulador en el divorcio. Respuestas a preguntas equivocadas», La Ley, 17/03/2015, 1, La Ley, 2015-B, p. 1134.

KIELMANOVICH, J. L., «¿Caducidad de oficio de la acción de compensación económica?» La Ley, 1, 03/05/2017-B, p. 1068.

LlOVERAS, N. y SALOMÓN, M., El Derecho de familia desde la Constitución Nacional, Buenos Aires (Editorial Universidad), 2009.

MAZZINGHI, E. (h.), «Revisión de las compensaciones económicas acordadas por los ex cónyuges o fijadas judicialmente», ponencia presentada por el autor en las Jornadas Nacionales de Derecho Civil La Plata, 28, 29 y 30 de septiembre de 2017. Disponible en $<\mathrm{http} / / /$ jornadasderechocivil.jursoc.unlp.edu.ar/wp-content/ uploads/sites/10/2017/08/Mazzinghi-Esteban-Revision-de-las-compensacioneseconomicas-Comisi\%C3\%B3n-8-2.pdf $>$. [Consultado el 7/11/2018].

MIZRAHI, M. L., «Compensación Económica. Pautas, Cálculo, Mutabilidad, Acuerdos y Caducidad», La Ley, 06/08/2018-D, p. 721.

MIZRAHI, M. L., Divorcio, alimentos y compensación económica, Buenos Aires (Astrea), 2018. 
MOLINA DE JUAN, M., Compensación Económica, Santa Fe (Rubinzal Culzoni), 2018.

NINO, C., Fundamentos de Derecho Constitucional. Análisis Filosófico, jurídico y politológico de la práctica constitucional, Buenos Aires (Astrea), 1992.

PELLEGRINI, M. V., «Compensaciones económicas: formas de cumplimiento, cuestiones posteriores a su fijación y posible superposición en los casos de uniones que cesan por matrimonio», Derecho de Familia. Revista Interdisciplinaria de Doctrina y Jurisprudencia, núm. 78, 2017. Disponible en <http://www.pensamientocivil. com.ar/doctrina/3732-dos-preguntas-inquietantes-compensacion-economica $>$. [Consultado el 7/11/2018].

PELLEGRINI, M. V., «Comentario al artículo 441 del CCyC», en KEMLEMAJER DE CARLUCCI, A.; HERRERA, M. y LLOVERAS, N. (dirs.), Tratado de Derecho de Familia, según código Civil y comercial 2014, Tomo I, Santa Fe (Rubinzal Culzoni), 2014, pp. 412-464.

SOLARI, N. E., «El plazo de caducidad en la compensación económica», La Ley, 1, 03/10/2017- E, 1, p. 1037. 